\title{
Strategies to Improve Patient Outcomes and QOL: Current Complications of the Design and Placements of Ureteric Stents
}

This article was published in the following Dove Press journal: Research and Reports in Urology

Meghana Ramachandra (D)

Ali Mosayyebi $\mathbb{D}^{2,3}$

Dario Carugo ${ }^{2,3}$

Bhaskar K Somani (DI)

'Department of Urology, University Hospital Southampton NHS Trust, Southampton, UK; ${ }^{2}$ Mechanical Engineering Department, Faculty of Engineering and the Environment, University of Southampton, Southampton, UK; ${ }^{3}$ Institute for Life Sciences (IfLS), University of Southampton, UK
Correspondence: Bhaskar K Somani Professor and Consultant Urological Surgeon, Wessex Clinical Research Network (CRN) and Simulation Lead for Urology, Department of Urology, University Hospital Southampton,

Southampton, UK

Tel +02381206873

Email bhaskarsomani@yahoo.com

\begin{abstract}
Ureteric stents have played a vital role in relieving urinary obstruction in many urological conditions. Although they are extremely successful, stents have been associated with complications and reduced patients' health-related quality of life (HRQoL). There are many factors that may affect the quality and longevity of stents. In this review, we have highlighted the journey and innovation of ureteric stents through the modern day. A literature review was conducted to identify relevant articles over the last 20 years. There is a plethora of evidence with various indications for the use of ureteral stents and how they affect QoL. There is still ongoing research to develop the ideal stent with reduced encrustation, one that resists infection and is also comfortable for the patients. Stents made from metal alloys, polymers and biodegradable materials have unique properties in their own right but also have certain deficiencies. These have been discussed along with an overview of newly developed stents. Certain pharmacological adjuncts have also been highlighted that may be useful to improve patient's tolerance to stents. In summary, this paper describes the features of the different types of stents and the problems that are frequently encountered, including effect on patients' HRQoL and financial burden to healthcare providers.
\end{abstract}

Keywords: ureteral stent, encrustation, health-related quality of life, infection, stent symptoms

\section{Introduction}

Ureteric stents help drainage of urine from the kidney to the bladder and thereby bypass internal and external obstruction of the urinary tract. ${ }^{1-10}$ With rising incidence of kidney stone disease (KSD), the use of stents is also likely to escalate. ${ }^{4}$ The indications for stenting have increased as surgical techniques have expanded over the last few decades. The absolute indications for stent insertion are obstructed pyelonephritis, bilateral ureteral obstruction, complete obstruction from benign or malignant conditions, obstruction of solitary functioning kidney, post ureteric surgery such as pyeloplasty or ureteric reimplantation, and ureteric injuries. Relative indications include post-procedural management of urolithiasis, pain relief due to ureteric obstruction, in partial nephrectomy, in pregnancy and pre-shockwave lithotripsy of large stones to prevent ureteral obstruction from stone fragments. ${ }^{5}$ The decision to use stents for other indications remains subjective.

Ureteric stents are used commonly by urologists worldwide and their failure rate can be high, with a negative impact on quality of life (QoL) in up to $80 \%$ of patients. ${ }^{6}$ Indwelling ureteral stents have been associated with complications and 
physical distress to the patients. ${ }^{7}$ The common reason of symptoms includes stent migration, ureterovesical reflux, tissue irritation, encrustation and biofilm formation (ie, particle deposition) that may lead to lower urinary tract infections (LUTS) ${ }^{8,9}$ Urinary tract infections (UTIs) and LUTS have been associated with ureteric stents, with the incidence of stent bacterial colonisation estimated to be at $90 \%$ in some reports. ${ }^{10}$ Occasionally, it might be beneficial to use other mechanisms of urinary diversion (UD) such as obstruction with underlying infection, small irritable bladders, underlying fistulae and high-pressure bladders. There has been a significant drive by clinicians and research groups to improve stent design thereby reducing the risk of complications, which could, in turn, improve patients' QoL. ${ }^{11}$ Therefore, the quest for an ideal ureteric stent still continues.

\section{Methods}

In this narrative review, published literature on ureteric stents from January 1990 to February 2020 is outlined. A systematic MEDLINE search was done using MeSH terms "ureteric stent", "double J stent", "stent biofilm", "stent encrustation", "stent bacterial colonisation", "stent design", "stent material", "stent coating" and "UTI".

\section{Innovation Driven by Patients' Health-Related Quality of Life (HRQoL) Outcomes}

The original stent design was similar to the modern day urinary catheters and they were commonly placed in the renal pelvis and exited outside the urethra, which made them highly susceptible to displacement. ${ }^{12}$ A modern day ureteric stent is a $22-32 \mathrm{~cm}$ long flexible polymeric tube with side holes. The "double-J" design, or commonly known as the pigtail design, was developed to reduce displacement. Nowadays, double-J ureteral stents are widely used and designed to anchor the stent in the renal pelvis and bladder to prevent migration. It can be deployed safely, is cost-effective and does not displace easily. ${ }^{13,14}$

The associated pain and other side effects have been quantified to evaluate their impact on the patients' QoL (Figure 1). There have been several attempts to improve patient tolerance to these ureteric stents (Table 1). A validated questionnaire called the Ureteral Stent Symptom Questionnaire (USSQ) was developed by Joshi et al to assess patient comfort after stent placement. ${ }^{5,15}$ It has been endorsed in several languages and used in studies to

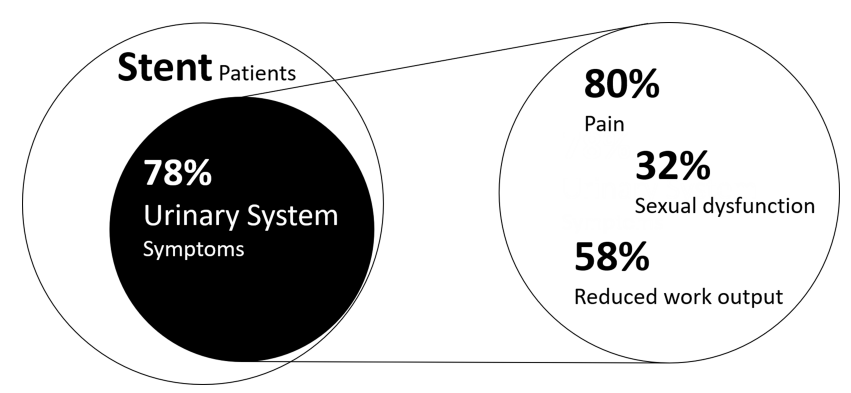

Figure I Effect of ureteric stent on patient symptoms and quality of life.

compare different types of stents and stented versus nonstented patients. An initial study reported that $78 \%$ of stentbearing patients complained of urinary symptoms; $80 \%$ of patients described pain due to the stent, $58 \%$ described reduced work output and $32 \%$ reported sexual dysfunction. ${ }^{5,15}$ Several studies have compared different types of ureteric stent and analysis has shown no ureteric stent to be superior to others. ${ }^{6}$ The common symptoms mentioned in these studies were frequency, dysuria, urgency, haematuria, flank pain, suprapubic pain and UTIs. ${ }^{16}$ Patient education and monitoring are important to ensure appropriate management and patient satisfaction. The necessity to improve stent tolerance has led to modifications of its

Table I Recent Innovations in Ureteral Stent Designs

\begin{tabular}{|c|c|c|}
\hline $\begin{array}{l}\text { Stent } \\
\text { Issues }\end{array}$ & Innovative Design & Reference \\
\hline Encrustation & $\begin{array}{l}\text { Coating agent against biofilm } \\
\text { formation }\end{array}$ & Szell et al ${ }^{61}$ \\
\hline $\begin{array}{l}\text { Bacterial } \\
\text { colonisation }\end{array}$ & Drug eluting stent & Lim et $\mathrm{al}^{62}$ \\
\hline $\begin{array}{l}\text { "Forgotten } \\
\text { stent" }\end{array}$ & Biodegradable stent & $\begin{array}{l}\text { Barros } \\
\text { et } \mathrm{al}^{37} \\
\text { Soria } \\
\text { et } \mathrm{al}^{39}\end{array}$ \\
\hline Migration & $\begin{array}{l}\text { Telescoping stent } \\
\text { Helical stent to control drainage } \\
\text { Non-coplanar pigtails to avoid } \\
\text { migration }\end{array}$ & $\begin{array}{l}\text { Pendleton } \\
\text { et al }^{40} \\
\text { DeGraaf } \\
\text { et al }{ }^{42} \\
\text { Yachia } \\
\text { et al }{ }^{43}\end{array}$ \\
\hline Urine reflux & $\begin{array}{l}\text { Proximal end - anchoring structure } \\
\text { and distal end }-J \text { tail into the renal } \\
\text { pelvis } \\
\text { Self-expandable mesh in the bladder } \\
\text { and valve mechanism to prevent reflux }\end{array}$ & $\begin{array}{l}\text { McMahon } \\
\text { et al }^{44} \\
\text { Shelton } \\
\text { et al }\end{array}$ \\
\hline
\end{tabular}


original design. Common type of stents include metallic stents $^{5,16,17}$ and polymeric stents. ${ }^{27-36}$

\section{Polymeric Stents and Their Clinical Use}

In recent years, polymers have been used to manufacture ureteral stents such as C-flex, Percuflex, Silitek, Dual Durometer, Sof-flex and Polyurethane stents. ${ }^{5}$ Polymers are thought to be inert and stents with external grooves on the lumen were manufactured to increase the surface area for urinary drainage and stone clearance. Stents augmented with metal wires, shaped into spiral design showed superior flow and drainage. ${ }^{27}$ To overcome bladder irritation in patients with ureteric stents, loops of polymer were incorporated instead of the classical pigtail at the distal end of the double-J stents. It was thought that this new "tail stent" would decrease bladder irritation. However, a study by Dunn et al demonstrated no significant difference in renal or flank pain between standard double-J stents and the new tail stents. ${ }^{28}$ With the motive to reduce bladder irritation and improve patient acceptance, a novel stent with a hard tip at the proximal end (kidney) and a softer tip at the distal end was developed. Dual-durometer and Percuflex ${ }^{\circledR}$ manufactured by Boston Scientific are examples of this modified tail stent. ${ }^{27}$
In a recent study, patients with "intra-ureteral" Polaris Loop stents (Boston Scientific, Marlborough, Massachusetts, USA) reported lower pain scores, lesser voiding symptoms on the International Prostate Symptom Score (IPSS) questionnaire and less analgesic use when compared to patients with standard double-J stents. However, there were no differences in stent-related complications. ${ }^{29}$ A porcine study of a segmental stent with a three-part design (proximal coil, braided mid-section and a distal nitinol basket for anchoring) showed its use in pyeloplasty to be safe and effective. ${ }^{30}$

\section{Metallic Stents and Their Clinical Use}

Researchers and commercial manufacturers have invested considerable time and resource to assess different stent parameters such as material used, size, shape and diameter to modernise ureteric stents; therefore, improving patients' quality of life (Table 1 and 2). ${ }^{5}$ Stents are made using metal alloys, polymers and biodegradable materials. Metal alloys are ductile, mouldable and stiff, providing resistance to compressive forces. Therefore, they are extremely suitable for manufacturing stents. ${ }^{5}$ Additional features such as selfexpanding, balloon expandable and thermo expandable make the double-J metal stent very versatile. Self-expandable mesh

Table 2 Materials and Coatings Used for Novel Stents

\begin{tabular}{|c|c|c|c|}
\hline $\begin{array}{l}\text { Type of } \\
\text { Material }\end{array}$ & Novel Material of Stents & Coating Used & Advantages/Key Points \\
\hline \multirow[t]{3}{*}{ Metal } & Nickel Titanium (Nitinol) & Hyaluronic acid & $\begin{array}{l}\text { Malleable - soft and durable } \\
\text { Not indicated in patients with functional stenosis or stone } \\
\text { formation }\end{array}$ \\
\hline & Stainless steel & Silver & $\begin{array}{l}\text { Easy to manufacture } \\
\text { Retrieval can be difficult }\end{array}$ \\
\hline & $\begin{array}{l}\text { MP35N alloy } \\
\text { (Nickel-cobalt-chromium - } \\
\text { molybdenum) }\end{array}$ & Hyaluronic acid & $\begin{array}{l}\text { Metallic pigtail stent with high tensile strength } \\
\text { Resistant to corrosion }\end{array}$ \\
\hline \multirow[t]{6}{*}{ Polymeric } & Silicone & Heparin & Highly biocompatible \\
\hline & Polyurethane & Polyvinylpyrrolodine & High drainage performance and high epithelial erosion \\
\hline & Silitek & Antibiotics & High tensile strength, weak coil retention, risk of oedema \\
\hline & Percuflex & $\begin{array}{l}\text { Chitosan } \\
\text { Hydrogel } \\
\text { Salicylic acid }\end{array}$ & $\begin{array}{l}\text { Cost effective, efficient urine drainage and coil retention } \\
\text { Low coil and tensile strength }\end{array}$ \\
\hline & C-Flex & Carbon & $\begin{array}{l}\text { Less surface friction, less particle adhesion, lower mechanical } \\
\text { strength }\end{array}$ \\
\hline & Dual durometer & & Reduced bladder irritation \\
\hline Biodegradable & & Triclosan & Reduced secondary procedures \\
\hline
\end{tabular}


stents were developed to facilitate urinary drainage and reduce urinary reflux. ${ }^{17}$ The idea behind the innovation was to use the mesh to reduce clogging and improve urine flow within the stent. ${ }^{18}$ These self-expanding mesh stents did not influence the mechanical properties of the ureter. ${ }^{19}$ Stents with broader lumen offer improved drainage and have been shown to have good efficacy in long-term urinary drainage. ${ }^{20}$ Titanium stents have been shown to be effective in reestablishing urinary flow when there is blockage or obstruction due to benign prostatic hyperplasia. ${ }^{21}$

The widely used metallic stents are made of nickel and titanium mixed alloys, and these have several advantages in terms of greater patency, longer indwelling time, less morbidity and better management of stricture. The unique property of these stents is the ability to soften at temperatures below $7-13^{\circ} \mathrm{C}$ and then regain their shape when there is a rise in temperature above $55^{\circ} \mathrm{C}$. This property makes the stent deployment and its removal technically feasible. ${ }^{22}$ The Allium stent manufactured from Nitinol wire is selfexpanding, segmented and packed between polymer strips (Table 3). ${ }^{23}$ They are made with nitinol for high radial force and covered with a copolymer that prevents tissue ingrowth and encrustation and are used for ureteric strictures, ureteric fistulas and uretero-ileal fistulas.

A study by Song et al demonstrated the viability of nitinol stents in urethral strictures' treatment as well. ${ }^{24}$ The Resonance stent is an alloy of nickel, cobalt, chromium and molybdenum. It does not have a lumen and the urine flows alongside the stent. ${ }^{25}$ A small study by Wah et al showed Resonance stent to have improved urine drainage over 1 year when compared with traditional double-J ureteral stents. ${ }^{26}$ The main disadvantages of metallic stents include ingrowth of tumour, epithelial hyperplasia, difficulty in removing impacted stents, higher cost and complexity of insertion. ${ }^{5}$

Table 3 Summary of Designs in Ureteral Stents

\begin{tabular}{|c|c|c|}
\hline $\begin{array}{l}\text { Type of } \\
\text { Design }\end{array}$ & Key Features & Examples \\
\hline Double-J & Commonly used design, reduced risk of migration & \\
\hline Double-J 3D & Provides better proximal and distal retention & Silicon Figure Four (SFF) (Bard ${ }^{\circledR}$ USA) \\
\hline Loop & Better patient comfort & $\begin{array}{l}\text { Polaris }{ }^{\mathrm{TM}} \text { Loop ureteral stent (Boston } \\
\text { Scientific }^{\circledR} \text {, USA) }\end{array}$ \\
\hline Mesh & Reduced risk of bladder irritation but technically demanding & $\begin{array}{l}\text { Uventa self expanding metallic mesh stent } \\
\text { (Taewoong Medical, Seoul, Korea) }\end{array}$ \\
\hline Expandable & High luminal flow, ease of insertion and retrieval & $\begin{array}{l}\text { Allium }{ }^{\circledR} \text { Ureteral stent (Allium Medical } \\
\text { Solutions }{ }^{\circledR} \text {, Israel) }\end{array}$ \\
\hline Magnetic tip & Allows effective retrieval & Magnetic Black-Star (Urovision, Germany) \\
\hline String & Facilitates stent removal by patient or surgeon in clinic & $\begin{array}{l}\text { Boston Scientific }{ }^{\circledR} \text {, USA; Cook }{ }^{\circledR} \text { Medical, } \\
\text { USA }\end{array}$ \\
\hline $\begin{array}{l}\text { Coil- } \\
\text { reinforced }\end{array}$ & Allows efficient drainage, reduces kinking and buckling & Silhouette ${ }^{\circledR}$ stent (Applied Medical USA) \\
\hline Basket & Allows passage of small stones and prevents migration of bigger stones & $\begin{array}{l}\text { Ureteral Stone Sweeper }{ }^{\circledR}\left(\text { Fossa }^{\circledR} \text { Medical, }\right. \\
\text { USA) }\end{array}$ \\
\hline Spiral Cut & Potentially fewer upper tract symptoms & Boston Scientific $^{\circledR}$, USA \\
\hline Helical & Better drainage of urine and passage of small stones & Boston Scientific $^{\circledR}$, USA \\
\hline Grooved & Suitable for post lithotripsy to enable passage of stone fragments & $\begin{array}{l}\text { Towers Peripheral Ureteral Stent }\left(\text { Cook }^{\circledR}\right. \\
\text { Medical, USA) }\end{array}$ \\
\hline $\begin{array}{l}\text { Streamlined } \\
\text { side-hole }\end{array}$ & $\begin{array}{l}\text { Providing reduced particle deposition by increasing the wall shear stress at side- } \\
\text { holes and enhancing fluid exchange between intra- and extra-luminal stent } \\
\text { compartments. }\end{array}$ & No clinical data available currently \\
\hline
\end{tabular}




\section{Stent Size and Length with Their Clinical Use}

Stent size can be modified by using different diameter or length as per clinical the need. Three different stent types were compared by Bellman et al, and there was no difference among the groups in terms of voiding symptoms, haematuria, pain, nocturia and incontinence. ${ }^{31}$ Another study showed that pain and irritative symptom scores were similar in groups comparing two Bard inlay ureteral stents with different diameters. ${ }^{32}$ A study by Ho et al showed that a longer stent was associated with substantially frequent urination, nocturia, urinary incontinence, haematuria and flank pain. ${ }^{33}$ Similar findings were confirmed by Al-Kandari et al where patients with longer stents had worse quality of life scores when compared to patients with shorter stents. ${ }^{34}$ However, multi-length stents are probably most used nowadays compared to fix sized stents, which maybe cost associated with keeping large inventory compared to one size fits all. Studies have focused on optimising ureteric stenting and evaluating the suitability of smaller stents. Patients with smaller stents for a reduced time period recorded better scores. These studies showed no differences between stone-free rates following planned and repeated unilateral ureteroscopy (URS). ${ }^{35}$ Based on previously discussed modifications, a dual-lumen stent with two drainage pathways was tested by Hafron et al and reported improved urine drainage when compared to single lumen stents in an ex vivo kidney model. ${ }^{36}$

\section{Variations in Stent Removal}

Standard stent removal is done using a cystoscope usually under a local anaesthetic. Other methods are biodegradable stents, stents with magnetic tip and stent with strings. ${ }^{37-52}$ Novel biodegradable ureteral stents were manufactured using Uriprene to improve urine drainage, provide good biocompatibility and avoid traditional removal. ${ }^{37}$ The issues with these stents included axial rigidity leading to difficult placement, non-uniform degradation and the biodegrading time of 10 weeks which was longer than typical indwelling stents. The potential disadvantages are the complete degradation over a few days which limits the use for very short-term stenting. Longer duration degradable stents were shown to last for up to 6-10 weeks (in porcine studies) but the disadvantages were increased bacteriuria. However, studies by Barros et al and Soria et al have demonstrated degradation in a predictable and controlled fashion with no obstructive fragments. ${ }^{37,39}$

Certain stents have strings attached to help removal and some have baskets to improve the passageway for small stones and stop bigger stones' migration through the ureter. ${ }^{4,38}$ There are other stents made from biodegradable/bioabsorbable metal mesh and some have polymeric flap valves to reduce reflux. Some studies have shown that these stents have improved patient comfort. ${ }^{5}$ However, cystoscopy is often required to remove stents and is associated with potential complications and increased healthcare costs. ${ }^{13}$

\section{Innovative New Stent Designs}

An online review of recent patents shows plenty of ureteric stent models that have been studied and investigated. A novel telescoping ureteral stent developed by $\mathrm{COOK}^{\circledR}$ Medical comprises a proximal structure (located towards the kidney) telescopically sliding into a distal structure (located towards the bladder). This invention stops the stent from migrating into the ureter and prevents the extended proximal end from returning back into the ureter. ${ }^{40}$ It comprises compressed springs without side holes and the indwelling stent can last for up to 12 months. ${ }^{41}$

A novel helical stent made of polymeric materials (Boston Scientific Corporation, Grove, MN, USA) developed to control urine drainage has been described by DeGraaf et al. It consists of filaments with controlled extensions combined with a dissolvable coating. ${ }^{42}$ Another novel stent invented by Yachia et al (Innoventions Ltd., Akiva, Israel) relies on having both pig-tail ends non-coplanar with respect to the bladder trigone. Different materials are used at either ends of the stent which also prevents urine reflux from the bladder and into the kidney. ${ }^{43}$ Similarly, another innovative stent to reduce ureterovesical reflux has a proximal J-end (kidney) and an anchoring structure at the bladder end. The lumen has been designed to have a narrower cross-section in the bladder, to reduce bladder irritation. A flapper valve was designed at the bladder end, which closes when the bladder pressure increases in order to prevent reflux. ${ }^{44}$ A series of self-expandable ureteral stents were designed by Gyrus ACMI ${ }^{\circledR}$ (Massachusetts, USA) with projections of different shape, length, size and orientation; these have been trialled to reduce urothelial tissue irritation, at the bladder trigone and ureterovesical junction (UVJ). It contains a self-expandable mesh structure anchoring to the UVJ and includes a valve mechanism to prevent reflux. $^{45}$ 


\section{Ongoing Issues with Ureteral Stents and Strategies for Improvement}

Stent designs have been constantly improving over the years, but the complication rate remains high. It has been established that side effects are directly proportional to the indwelling time of these stents. Therefore, removing the stent as early as possible is the best remedy to reduce the unwanted side effects and complications. ${ }^{46}$ There have been reports where insertion of a stent can also cause displacement towards the kidney due to their effects of ureteric peristalsis. ${ }^{47}$

\section{Stent Removal Issues}

Stents need to be removed via flexible cystoscopy in the outpatient (OP) clinic or in the operating room (OR). A number of modern stents have integrated extraction strings and the patients can remove it themselves or the surgeon can remove them in the OP clinic. ${ }^{38}$ The extraction strings are made of fine suture material secured to the distal end of the stent, runs through the urethra and is visible at the urethral meatus. The string can be left free or secured to the patient on the mons pubis or thigh in women or to the penis in men. A systematic review by Oliver et al concluded that the majority of patients were able to remove the stents at home safely with reduced incidence of morbidity. ${ }^{38,48}$ However, there is some evidence of increased lower urinary tract symptoms (LUTS) due to string irritation, stent dislodgement, infection, stent retention and broken strings. Up to $10 \%$ of these stents are expelled spontaneously. The advantages include patient self-removal, reduced stent dwell time, duration of morbidity, physical and financial burden to patients.

Magnetic tipped stents were developed to aid stent removal without the need for cystoscopy. ${ }^{49}$ Studies by Netto et al and Taylor et al have demonstrated the costeffectiveness and efficacy of this. ${ }^{50,51}$ A randomised control trial by Rassweiler et al showed that a magnetic double-J stent removal was significantly less painful than the cystoscopic removal of the double-J stent. ${ }^{52}$ Urotech (Achen, Muhle) developed a double-J stent with a small magnet attached to the distal coil which remained in the bladder. The idea is to insert another 9-Fr retrieval catheter which had a complementary magnet on its tip and the ureteral stent in situ could then be retrieved without direct visualisation. ${ }^{13}$

\section{Issues with Urinary Tract Infections}

Stent placement can lead to urinary tract infections (UTIs) in high-risk patients (diabetes and chronic kidney disease) and in those with prolonged indwelling time..$^{53,54}$ The surface within the stent provides an environment for colonisation by bacteria to form a biofilm. Paick et al demonstrated the presence of bacterial colonisation in over $50 \%$ of patients with ureteral stents. ${ }^{55}$ Other studies have confirmed the presence of multiple Gram-positive and Gram-negative species on ureteral stents and antibiotic therapy has been shown to be ineffective. There is a significant association with encrustation, another common complication in ureteral stents. ${ }^{10}$ Stent infections can be minimised by reducing the stent usage and dwell time. For patients with long-term stents,

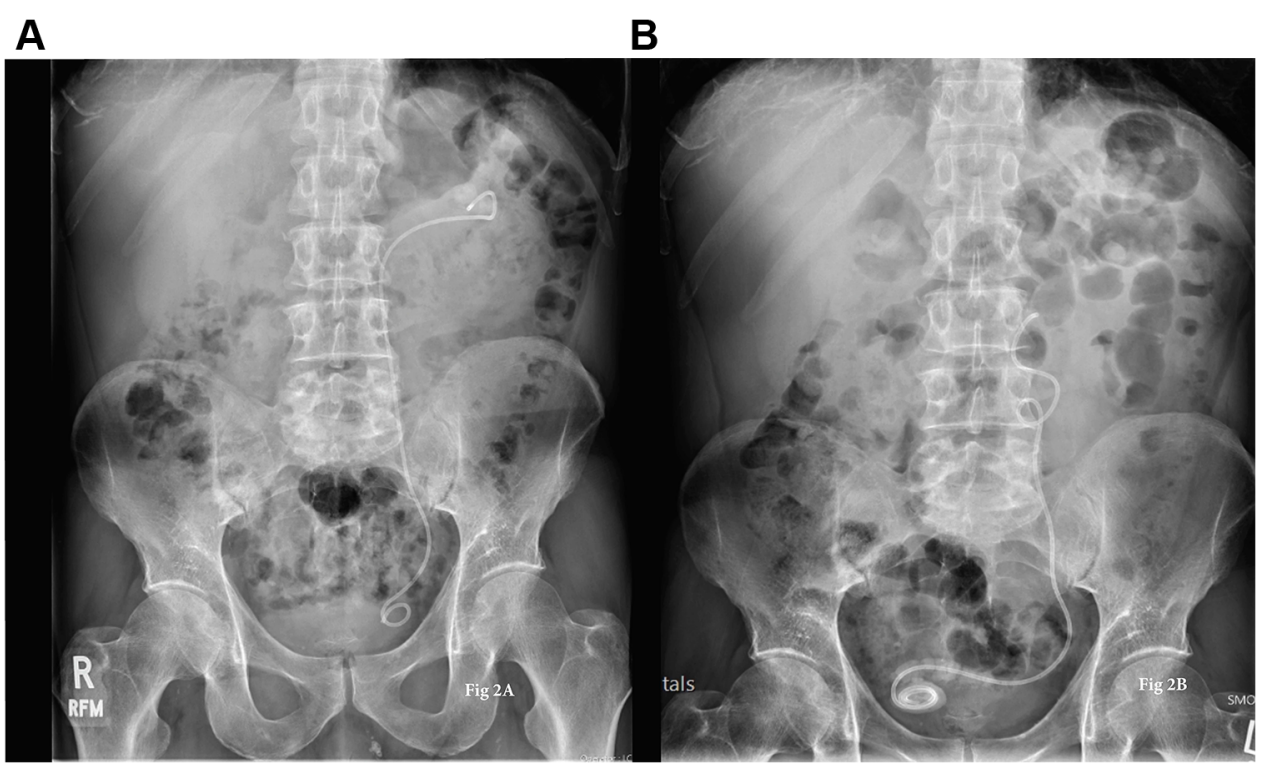

Figure 2 (A): Normal stent position. (B): Stent displaced, crossing the midline with encrusted bladder coil of the stent. 
changing the stents is sometimes helpful to decrease recurrent UTIs as the stents are colonised by the bacteria. ${ }^{49,50}$

\section{Issues with Stent Encrustations}

Encrustation is a common complication of stents, and on occasions, surgical intervention is necessary to retrieve and/ or replace the stent (Figure 2). The various factors effecting stent encrustation are urine composition, stent material, surface properties, stent design and dwell time, urinary $\mathrm{pH}$ and urine flow dynamics. ${ }^{9,41}$ It has been attributed to the presence of bacteria (such as Proteus mirabilis) known to produce urease. This leads to increase in urinary $\mathrm{pH}$ and crystal formation. ${ }^{56}$ A grading system - "Forgotten, encrusted and calcified" was advocated to characterise the encrustation and calcification. ${ }^{57,58}$ The newer generation of inert biodegradable ureteral stents may resist biofilm formation and reduce encrustation. It is important that the stents are in place for the minimum amount of time and should be removed as early as possible. This has been associated with complications such as infection, sepsis, migration and fistula formation. Occasionally, these "forgotten" stents are identified when the patient undergoes abdominal imaging. ${ }^{59,60}$ Silicone stents have been shown to reduce encrustations, and while the stent duration should be minimised, long-term stents should be used in patients who are stent-dependent for ureteric drainage. ${ }^{3}$

\section{Issues with Stent Biofilms}

To prevent biofilm formation on stents, coating of polyhydrogel (poly N,N-dimethylacryleamide) with antifouling and protein repellent properties has been used by Szell et al. In vitro studies showed a 5-fold decrease of bacterial load on the stent surface. ${ }^{61}$ By coating hydrophilic hydrogels on certain stents (Universa ${ }^{\circledR}$ Soft Ureteral Stent; $\mathrm{COOK}^{\circledR}$ Medical, Bloomington, USA) deployment has become easier and effective due to reduced surface friction and improved lubrication. The hydrogel layer prevents the drug being washed away by the urine flow and this property can make the stent very effective in treatment of conditions affecting the urothelium such as tumours and strictures. This concept allowed Lim et al to develop a drug-eluting ureteric stent to ensure a sustained drug release over 4-6 weeks and improved drug absorption by the urothelium. An in vivo porcine study was shown to be safe with no evidence of hydronephrosis or systemic toxicity. $^{62}$ In certain self-expanding ureteric stents, the mesh can be used as a reservoir for elution of pharmacological agents. ${ }^{63}$ Anti-inflammatory and anti-cancer agents have also been incorporated in these stents with favourable outcomes. ${ }^{64}$ However, these stents are technically challenging with mixed results and involve high costs. ${ }^{17}$

\section{Stent Coating to Reduce Complications}

A succinct synopsis by Mosayyebi et al has highlighted several strategies that are helpful to reduce biofilm and encrustation. $^{41}$ These include using different metallic alloys to produce stents (nitinol, superalloy titanium and chromium cobalt) as they have shown different tendencies to encrustation. In an in vivo study, the new generation spiral cut stents showed no significant reduction in encrustation, infection rate and stent migration. ${ }^{65}$ The best resistance against encrustation was achieved by silicone, followed by polyurethane stents. ${ }^{20,66}$ To prevent biofilm, heparin (anti-coagulant), diamond-like carbon (DLC) and hydrogel coatings have been used, to coat the stents with moderate success in various in vivo and in vitro studies. John et al demonstrated that hydrogel did not reduce bacterial load but integrated well with antibiotics. ${ }^{67}$ The efficacy of antibiotic-coated ureteral stents has proven to be successful in reducing bacterial load, although combination of antibiotics was often found to be more effective. $^{68-71}$ Other anti-microbial agents described are polytetrafluoroethylene (PTFE), triclosan, silver and chitosan. These materials also have another unique property of reduced coefficient of friction, allowing efficient urine flow and reduced bacterial growth. ${ }^{72-75}$

\section{Stent Malpositioning}

Improper placement is associated with haematoma or urinoma due to penetration and iatrogenic damage. ${ }^{76}$ Stent migration can occur due to peristalsis, more so when the stent is made of softer materials or if coated with hydrophilic material (Figure 2). This can be avoided by using a double-J or pigtail stent design. Imaging modalities play a vital role in identifying the stent position. Polyurethane stents have been recognised to have better shape memory and can conform to the urinary tract when compared to silicone, reducing the incidence of ureteral stent migration. However, stent fractures have been observed in the ones made of polyethylene and it has been attributed to crystallisation and encrustation. ${ }^{77}$

\section{Stent Erosion}

Ureteral erosion and fistula formation are rare and potentially devastating and can happen due to erosion of the adjacent arterial system. Intermittent haematuria in 
a patient with a stent is a common presentation, and massive haematuria leading to circulatory collapse may occur when stent is manipulated. Extensive pelvic surgery and irradiation have been associated with fistula formation as it is thought that both may lead to ureteral ischaemia. Diagnosis can be difficult, and angiogram is the gold standard. Management of the fistula can be done via open procedure and interventional radiology technique or a combination of both. ${ }^{78,79}$

\section{Stent Blockages}

Failure to relieve obstruction is usually caused by haematuria, increased viscosity of urine and debris deposition affecting the stent lumen. Therefore, in some patients, stents with larger lumen diameter (7Fr-10Fr) should be used..$^{5}$ Although stent blockages are relatively uncommon, diagnosis is usually made by recurrence of symptoms such as loin pain, confirmed by either deterioration of renal function or presence of hydronephrosis on scans. Treatment is usually stent replacement, although alkaline medication such as sodium or potassium citrate can also reduce encrustations. $^{12,13}$

\section{Pharmacological Strategies to Improve Stent-Related Symptoms}

\section{Alpha Blockers}

The American Urological Association and Endourology Society guidelines recommended medications to reduce stent discomfort. ${ }^{80}$ The most commonly used alphablockers (alpha-adrenoreceptors antagonists) after ureteral stent insertion are tamsulosin, alfuzosin and terazosin. ${ }^{5}$ Liu et al demonstrated that patients on alfuzosin regimen following ureteral stent insertion had significantly lower IPSS and visual analogue scale (VAS) scores in the initial period. ${ }^{81}$ Wang et al showed that patients undergoing insertion of double-J stents after ureteroscopic stone removal had better pain relief when given tamsulosin, when compared to patients given placebo. ${ }^{82}$ Gupta et al demonstrated significant reduction in post-operative pain and narcotic use after injection of botulinum toxin type A, but no differences in irritative symptoms. ${ }^{83}$

\section{Anticholinergics}

Anticholinergic agents decrease voiding symptoms through direct actions on the muscarinic receptors present in the bladder. A randomised controlled trial reported that the patients undergoing double-J stent placement after ureteroscopy and laser lithotripsy receiving solifenacin showed significantly lower total symptom scores urgency and urge incontinence, flank, abdominal, urethral pain and haematuria. ${ }^{84}$

\section{Beta-3 Adrenergic Agonists}

A well-designed multi-centre randomised controlled trial investigated the use of Mirabegron during the stenting period and the patients' outcomes were recorded using two validated questionnaires - International Prostate Symptom Score (IPSS) and Ureteral Stent Symptom Questionnaire (USSQ). The authors concluded that $50 \mathrm{mg}$ Mirabegron had the potential to reduce ureteric stent-related discomfort. ${ }^{85}$

A large RCT by Ragab et al highlighted that patients with both pregabalin and solifenacin had better USSQ scores and pregabalin alone was well tolerated and safe in patients with stent-related symptoms. ${ }^{86,87}$ A small study by Tharwat et al showed that sildenafil was tolerated in men with ureteral-related symptoms. ${ }^{19}$ A combination therapy with tamsulosin and oxybutynin has been shown to be effective in improving irritative symptoms, work performance and sexual function. ${ }^{88}$ The meta-analysis by Zhang et al concluded that there are significant advantages of combination therapy when compared to monotherapy with alpha-blockers based on the International Prostate Symptom Score (IPSS). ${ }^{89}$

\section{Improvement of Quality of Life and Future Areas of Interest}

The presence of ureteric stents effects patient QoL. More work needs to be invested on improving stent design, material and coating, and minimise stent usage and stent dwell time. The dwell time can increase stent-related complications such as urinary tract infections, sepsis and stent encrustations. ${ }^{90}$ Patients also need to be better informed about stent-related symptoms and communication is vital through counselling and patient information leaflets. ${ }^{91}$ Similarly, stent registries and timely stent removal are also of utmost importance. ${ }^{92}$

The incidence of kidney and ureteric stones will increase over time, leading to more procedures and stent usage related to it. ${ }^{93,94}$ It is prudent to have mechanisms in place to shorten the dwell time using office-based ISIRIS disposable cystoscope stent removal, stent on string or magnetic stents. ${ }^{95}$ Stent positioning and antimicrobial coated stents might also need further investigating. ${ }^{96,97}$ Similarly, pre-stenting prior 
to ureteroscopy should be avoided thereby avoiding unnecessary stenting of patients. Future work would need to be done on biodegradable stents and coated stents, although patient involvement and use of patient-reported outcome measure and validated stent questionnaire would be helpful in understanding and comparing these stents.

\section{Conclusion}

Placement of ureteral stents has been common practice in the management of various urological conditions. Most patients experience stent-related side effects, and some have complications related to it. The ureteral stents have evolved over the years with new innovations in materials, coatings and designs. Quality of life outcomes have been one of the key factors behind the constant innovation and evolution. Standard practice must include patient education, stent monitoring and removal at the appropriate time. It is important that these patients with stents be monitored via emails, mobile-based app reminder systems. Moreover, further scientific efforts are required to develop stents that improve patients' QoL and reduce the financial burden for healthcare providers arising from clinical complications. In summary, the key features of an ideal stent should reduce patient discomfort and pain, improve urinary drainage, reduce incidence of encrustation and allow easy removal with minimal complications and morbidity.

\section{Disclosure}

The authors declare no conflict of interest.

\section{References}

1. Staubli SE, Mordasini L, Engeler DS, Sauter R, Schmid HP, Abt D. Economic Aspects of Morbidity Caused by Ureteral Stents. Urol Int. 2016;97(1):91-97. doi:10.1159/000443379

2. New F, Somani BK. A complete world literature review on quality of life (QOL) in patients with kidney stone disease (KSD). Curr Urol Rep. 2016;17(12):88. doi:10.1007/s11934-016-0647-6

3. Mosayyebi A, Vijayakumar A, Yue QY, et al. Engineering solutions to ureteral stents: material, coating and design. Central Eur $j$ Urol. 2017;70(3):270-274. doi:10.5173/ceju.2017.1520

4. Rukin NJ, Siddiqui ZA, Chedgy ECP, et al. Trends in upper tract stone disease in England: evidence from the hospital episodes statistics database. Urol Int. 2017;98(4):391-396. doi:10.1159/000449510

5. Sali GM, Joshi HB. Ureteric stents: overview of current clinical applications and economic implications. Int J Urol. 2020;27(1):7-15. doi:10.1111/iju.14119

6. Lingeman JE, Preminger GM, Goldfischer ER, Krambeck AE. Assessing the Impact of Ureteral Stent Design on Patient Comfort. J Urol. 2009;181(6):2581-2587. doi:10.1016/j.juro.2009.02.019

7. Davenport K, Kumar V, Collins J, Melotti R, Timoney AG, Keeley FX Jr. New ureteral stent design does not improve patient quality of life: a randomized, controlled trial. $J$ Urol. 2011;185(1):175-178. doi:10.1016/j.juro.2010.08.089
8. Harber M. Management of the Nephrotic Patient: the Overall Approach to the Patient with Nephrotic Syndrome (NS).. In: Harber M, editor. Practical Nephrology. London: Springer; 2014.

9. Mosayyebi A, Somani B, Zhang X, et al. Particle Accumulation in Ureteral Stents Is Governed by Fluid Dynamics: in Vitro Study Using a "Stent-on-Chip" Model. J Endourol. 2018;32(7):639-646. doi:10. 1089/end.2017.0946

10. Kehinde EO, Rotimi VO, Al-Hunayan A, Abdul-Halim H, Boland F, Al-Awadi KA. Bacteriology of urinary tract infection associated with indwelling J ureteral stents. J Endourol. 2004;18(9):891-896. doi:10. 1089/end.2004.18.891

11. De Grazia A, Somani BK, Soria F, Carugo D, Mosayyebi A. Latest advancements in ureteral stent technology. Transl Androl Urol. 2019;8(Suppl 4):S436-S41. doi:10.21037/tau.2019.08.16

12. Williams KGBA, Kumar P, Kumar P. Ureteric stents: the past, present and future. J Clin Urol. 2018;11(4):280-284. doi:10.1177/205141 5817722934

13. Lundeen CJ, Forbes CM, Wong VKF, Lange D, Chew BH. Ureteral stents: the good the bad and the ugly. Curr Opin Urol. 2020;30 (2):166-170. doi:10.1097/MOU.0000000000000701

14. Reynard J, Brewster SF, Biers S, Neal NL. Oxford Handbook of Urology. Oxford Univercity Press. 2019.

15. Joshi HB, Newns N, Stainthorpe A, MacDonagh RP, Keeley FX, Timoney AG. Ureteral Stent Symptom Questionnaire: development and Validation of a Multidimensional Quality of Life Measure. J Urol. 2003;169(3):1060-1064. doi:10.1097/01.ju.0000049198.53424.1d

16. Joshi HB, Chitale SV, Nagarajan M, et al. A prospective randomized single-blind comparison of ureteral stents composed of firm and soft polymer. $J$ Urol. 2005;174(6):2303-2306. doi:10.1097/01.ju.0000 $181815.63998 .5 \mathrm{f}$

17. Olweny EO, Portis AJ, Sundaram CP, et al. Evaluation of a chronic indwelling prototype mesh ureteral stent in a porcine model. Urology. 2000;56(5):857-862. doi:10.1016/S0090-4295(00)00734-2

18. Darren T, Beiko BEK, John D. Denstedt. Advances in Ureteral Stent Design. J Endourol. 2003;17(4):195-199. doi:10.1089/089277903765 444294

19. Tharwat M, Elsaadany MM, Lashin AM, El-Nahas AR. A randomized controlled trial evaluating sildenafil citrate in relieving ureteral stent-related symptoms. World $J$ Urol. 2018;36 (11):1877-1881. doi:10.1007/s00345-018-2339-y

20. Al Aown A, Iason K, Panagiotis K, Liatsikos E. Clinical experience with ureteral metal stents. Indian J Urol. 2010;26(4):474-479. doi:10.4103/0970-1591.74432

21. Kirby RS, Heard SR, Miller P, et al. Use of the ASI Titanium Stent in the Management of Bladder Outflow Obstruction Due to Benign Prostatic Hyperplasia. J Urol. 1992;148(4):1195-1197. doi:10.1016/ S0022-5347(17)36858-1

22. Athanasios G, Papatsoris NB. A Novel Thermo-Expandable Ureteral Metal Stent for the Minimally Invasive Management of Ureteral Strictures. J Endourol. 2010;24(3):487-491. doi:10.1089/end.2009.0138

23. Khoo CC, Abboudi H, Cartwright R, El-Husseiny T, Dasgupta R. Metallic Ureteric Stents in Malignant Ureteric Obstruction: A Systematic Review. Urology. 2018;118:12-20. doi:10.1016/j. urology.2018.01.019

24. Song H-Y, Park H, Suh T-S, et al. Recurrent Traumatic Urethral Strictures near the External Sphincter: treatment with a Covered, Retrievable, Expandable Nitinol Stent-Initial Results. Radiology. 2003;226(2):433-440. doi:10.1148/radiol.2262012160

25. Patel C, Loughran D, Jones R, Abdulmajed M, Shergill I. The resonance $^{\circledR}$ metallic ureteric stent in the treatment of chronic ureteric obstruction: a safety and efficacy analysis from a contemporary clinical series. BMC Urol. 2017;17(1):16. doi:10.1186/s12894-017-0204-8

26. Wah TM, Irving HC, Cartledge J. Initial Experience with the Resonance Metallic Stent for Antegrade Ureteric Stenting. Cardiovasc Intervent Radiol. 2007;30(4):705-710. doi:10.1007/ s00270-007-9043-4 
27. Ben H, Chew KAR, Ryan F, McDougall E, Paterson RF, Lange D. Percuflex Helical Ureteral Stents Significantly Reduce Patient Analgesic Requirements Compared to Control Stents. J Endourol. 2017;31(12):1321-1325. doi:10.1089/end.2017.0349

28. Matthew D, Dunn AJP, Scott A, et al. Clinical Effectiveness of New Stent Design: randomized Single-Blind Comparison of Tail and Double-Pigtail Stents. $J$ Endourol. 2000;14(2):195-202. doi:10.1089/end.2000.14.195

29. Davenport K, Kumar V, Collins J, Melotti R, Keeley FX, Timoney AG. Prospective randomised trial comparing the Bard Inlay ${ }^{\mathrm{TM}}$ ureteric stent with the boston scientific polaris ${ }^{\mathrm{TM}}$ ureteric stent using the validated ureteric stent symptom questionnaire. Eur Urol Supp. 2008;7(3):107. doi:10.1016/S1569-9056(08) 60145-1

30. Soria F, Morcillo E, de la Cruz JE, et al. Antireflux ureteral stent proof of concept assessment after minimally invasive treatment of obstructive uropathy in animal model. Arch Esp Urol. 2018;71 (7):607-613.

31. Bellman J. Ureteral Stents: impact of Diameter and Composition on Patient Symptoms. J Endourol. 1997;11(1):45-47. doi:10.1089/ end.1997.11.45

32. Erdal Erturk AS, Joseph JV, Joseph JV. Impact of Ureteral Stent Diameter on Symptoms and Tolerability. J Endourol. 2003;17 (2):59-62. doi:10.1089/08927790360587342

33. Chen-Hsun Ho S-C-C, Shiu-Dong C, Yuan-Ju L, et al. Determining the Appropriate Length of a Double-Pigtail Ureteral Stent by Both Stent Configurations and Related Symptoms. J Endourol. 2008;22 (7):1427-1432. doi:10.1089/end.2008.0037

34. Ahmed M, Al-Kandari TFA-S, Hamdy M, et al. Rapid Communication: effects of Proximal and Distal Ends of Double-J Ureteral Stent Position on Postprocedural Symptoms and Quality of Life: A Randomized Clinical Trial. J Endourol. 2007;21 (7):698-702. doi:10.1089/end.2007.9949

35. Cubuk A, Yanaral F, Ozgor F, et al. Comparison of 4.8 Fr and 6 Fr ureteral stents on stent related symptoms following ureterorenoscopy: A prospective randomized controlled trial. Kaohsiung J Med Sci. 2018;34(12):695-699. doi:10.1016/j.kjms.2018.07.001

36. Hafron J, Ost MC, Tan BJ, et al. Novel dual-lumen ureteral stents provide better ureteral flow than single ureteral stent in ex vivo porcine kidney model of extrinsic ureteral obstruction. Urology. 2006;68(4):911-915. doi:10.1016/j.urology.2006.05.025

37. Barros AA, Oliveira C, Ribeiro AJ, et al. In vivo assessment of a novel biodegradable ureteral stent. World J Urol. 2018;36 (2):277-283. doi:10.1007/s00345-017-2124-3

38. Oliver R, Wells $\mathrm{H}$, Traxer $\mathrm{O}$, et al. Ureteric stents on extraction strings: a systematic review of literature. Urolithiasis. 2018;46 (2):129-136. doi:10.1007/s00240-016-0898-1

39. Soria F, Morcillo E, Serrano A, et al. Evaluation of a New Design of Antireflux-biodegradable Ureteral Stent in Animal Model. Urology. 2018;115:59-64. doi:10.1016/j.urology.2018.02.004

40. Steven L, Pendleton GLN, Benjamin T. Biltz, inventor; Cook Medical Technologies LLC, assignee. Telescoping Ureteral Stent. 2018.

41. Mosayyebi A, Manes C, Carugo D, Somani BK. Advances in Ureteral Stent Design and Materials. Curr Urol Rep. 2018;19(5):35. doi:10.1007/s11934-018-0779-y

42. Kimberly DeGraaf TPH, Mark W. BodenJan Seppala, inventor; Boston Scientific Scimed Inc, assignee. Controlled Extension Stent. 2017.

43. Daniel Yachia VP, inventor; INNOVENTIONS Ltd, assignee. Stent and Method of Use; 2016.

44. Charles Wesley McMahon CAN, Danielle Rae S, Lisa Jin C, Maria Guadalupe A, Sara L. Pelayo, inventor; Baylor University, assignee. Ureteral stent and method2017.

45. Kurt G, Shelton AEP, inventor; Gyrus ACMI Inc, assignee. Ureteral stent with anti-migration features 2015.
46. Brooks AJ, Mahoney PF, Rowlands B. ABC of Tubes, Drains, Lines and Frames. John Wiley \& Sons; 2009.

47. Lennon GM, Thornhill JA, Grainger R, McDermott TED, Butler MR. Double Pigtail Ureteric Stent versus Percutaneous Nephrostomy: effects on Stone Transit and Ureteric Motility. Eur Urol. 1997;31 (1):24-29. doi:10.1159/000474413

48. Althaus A, Li K, Pattison E, Eisner B, Pais V, Steinberg P. PD7-03 Rate of accidental dislodgement of ureteral stents when utilizing an extraction string after endoscopic urologic surgery. J Urol. 2014;191 (4S):e184-e. doi:10.1016/j.juro.2014.02.692

49. Chew BH, Seitz C. Impact of ureteral stenting in ureteroscopy. Curr Opin Urol. 2016;26(1):76-80. doi:10.1097/MOU.0000000000000234

50. Netto NR Jr, Ikonomidis J, Zillo C. Routine ureteral stenting after ureteroscopy for ureteral lithiasis: is it really necessary? $J$ Urol. 2001;166(4):1252-1254. doi:10.1016/S0022-5347(05)65747-3

51. Taylor WN, McDougall IT. Minimally invasive ureteral stent retrieval. $J$ Urol. 2002;168(5):2020-2023. doi:10.1016/S00225347(05)64286-3

52. Marie-Claire Rassweiler M-SM, Manuel R, Honeck P, Honeck P. Magnetic Ureteral Stent Removal Without Cystoscopy: A Randomized Controlled Trial. J Endourol. 2017;31(8):762-766. doi:10.1089/end.2017.0051

53. Kehinde EO, Rotimi VO, Al-Awadi KA, et al. Factors predisposing to urinary tract infection after $\mathrm{j}$ ureteral stent insertion. $J$ Urol. 2002;167(3):1334-1337. doi:10.1016/S0022-5347(05)65294-9

54. Klis R, Korczak-Kozakiewicz E, Denys A, Sosnowski M, Rozanski W. Relationship between urinary tract infection and self-retaining Double-J catheter colonization. J Endourol. 2009;23 (6):1015-1019. doi:10.1089/end.2008.0518

55. Paick SH, Park HK, Oh S-J, Kim HH. Characteristics of bacterial colonization and urinary tract infection after indwelling of double-J ureteral stent. Urology. 2003;62(2):214-217. doi:10.1016/ S0090-4295(03)00325-X

56. Wilks SA, Fader MJ, Keevil CW. Novel Insights into the Proteus mirabilis Crystalline Biofilm Using Real-Time Imaging. PLoS One. 2015;10(10):e0141711. doi:10.1371/journal.pone.0141711

57. Benjamin K, Canales LH, Qin A, Anderson L, Li QA, Monga M. Presence of Five Conditioning Film Proteins Are Highly Associated with Early Stent Encrustation. J Endourol. 2009;23(9):1437-1442. doi:10.1089/end.2009.0389

58. Alex M, Acosta-Miranda JM, Thomas M. The FECal Double-J: A Simplified Approach in the Management of Encrusted and Retained Ureteral Stents. $J$ Endourol. 2009;23(3):409-415. doi:10.1089/end.2008.0214

59. Brian A, Vanderbrink ARR, Michael C, Smith AD. Encrusted Urinary Stents: evaluation and Endourologic Management. $J$ Endourol. 2008;22(5):905-912. doi:10.1089/end.2006.0382

60. Abdelaziz AY, Fouda WB, Mosharafa AA, Abelrasoul MA, Fayyad A, Fawzi K. Forgotten ureteral stents: risk factors, complications and management. Afr J Urol. 2018;24(1):28-33. doi:10.1016/j. afju.2017.09.005

61. Szell TFFD, Goelz H, Bluemel B, et al. In Vitro Effects of a Novel Coating Agent on Bacterial Biofilm Development on Ureteral Stents. $J$ Endourol. 2019;33(3):225-231. doi:10.1089/end.2018.0616

62. Lim WS, Chen K, Chong TW, et al. A bilayer swellable drug-eluting ureteric stent: localized drug delivery to treat urothelial diseases. Biomaterials. 2018;165:25-38. doi:10.1016/j.biomaterials.2018.02.035

63. Anis RR, Karsch KR. The future of drug eluting stents. Heart. 2006;92(5):585-588. doi:10.1136/hrt.2005.068288

64. Liatsikos EN, Karnabatidis D, Kagadis GC, et al. Application of Paclitaxel-Eluting Metal Mesh Stents within the Pig Ureter: an Experimental Study. Eur Urol. 2007;51(1):217-223. doi:10.1016/j. eururo.2006.05.054

65. Mucksavage P, Pick D, Haydel D, et al. An In Vivo Evaluation of a Novel Spiral Cut Flexible Ureteral Stent. Urology. 2012;79 (3):733-737. doi:10.1016/j.urology.2011.10.062 
66. Liatsikos E, Karnabatidis D, Kallidonis P, Siablis D. 5 - Metal stents in the upper urinary tract. In: Denstedt J, Atala A, editors. Biomaterials and Tissue Engineering in Urology. Woodhead Publishing; 2009:104-133.

67. Cauda FVC, Fiori C, Onida B, et al. Heparin Coating on Ureteral Double J Stents Prevents Encrustations: an in Vivo Case Study. J Endourol. 2008;22(3):465-472. doi:10.1089/end.2007.0218

68. Lo J, Lange D, Chew BH. Ureteral stents and foley catheters-associated urinary tract infections: the role of coatings and materials in infection prevention. Antibiotics. 2014;3(1):87-97. doi:10.3390/antibiotics3010087

69. Raad I, Hanna H, Jiang Y, et al. Comparative Activities of Daptomycin, Linezolid, and Tigecycline against Catheter-Related Methicillin-Resistant Staphylococcus Bacteremic Isolates Embedded in Biofilm. Antimicrob Agents Chemother. 2007;51(5):1656-1660. doi:10.1128/AAC.00350-06

70. Rose WE, Poppens PT. Impact of biofilm on the in vitro activity of vancomycin alone and in combination with tigecycline and rifampicin against Staphylococcus aureus. J Antimicrob Chem. 2008;63 (3):485-488. doi:10.1093/jac/dkn513

71. Minardi D, Cirioni O, Ghiselli R, et al. Efficacy of Tigecycline and Rifampin Alone and in Combination against Enterococcus faecalis Biofilm Infection in a Rat Model of Ureteral Stent. J Surg Res. 2012;176(1):1-6. doi:10.1016/j.jss.2011.05.002

72. Lange D, Elwood CN, Choi K, Hendlin K, Monga M, Chew BH. Uropathogen Interaction With the Surface of Urological Stents Using Different Surface Properties. J Urol. 2009;182(3):1194-1200. doi:10.1016/j.juro.2009.05.008

73. Nowatzki PJ, Koepsel RR, Stoodley P, et al. Salicylic acid-releasing polyurethane acrylate polymers as anti-biofilm urological catheter coatings. Acta Biomater. 2012;8(5):1869-1880. doi:10.1016/j. actbio.2012.01.032

74. Carlson RP, Taffs R, Davison WM, Stewart PS. Anti-biofilm properties of chitosan-coated surfaces. J Biomater Sci Polym Ed. 2008;19 (8):1035-1046. doi:10.1163/156856208784909372

75. Yang S-H, Lee Y-SJ, Lin F-H, Yang J-M, Chen K-S. Chitosan/poly (vinyl alcohol) blending hydrogel coating improves the surface characteristics of segmented polyurethane urethral catheters. J Biomed Mater Res B Appl Biomater. 2007;83B(2):304-313. doi:10.1002/jbm. b.30796

76. Dyer RB, Chen MY, Zagoria RJ, Regan JD, Hood CG, Kavanagh PV. Complications of Ureteral Stent Placement. RadioGraphics. 2002;22 (5):1005-1022. doi:10.1148/radiographics.22.5.g02se081005

77. Bach Christian DD. Chapter-30 Prostate Stents: Indications. Handbook of Urinary Stents: Basic Science and Clinical Applications; 2016.

78. Bergqvist D, Pärsson H, Sherif A. Arterio-ureteral fistula-a systematic review. Eur J Vasc Endovasc Surg. 2001;22(3):191-196. doi:10.1053/ejvs.2001.1432

79. Smith RB. Ureteral Common Iliac Artery Fistula: A Complication of Internal Double-J Ureteral Stent. J Urol. 1984;132(1):113. doi:10.1016/S0022-5347(17)49490-0

80. Assimos D, Krambeck A, Miller NL, et al. Surgical Management of Stones: american Urological Association/Endourological Society Guideline, PART I. J Urol. 2016;196(4):1153-1160. doi:10.1016/j. juro.2016.05.090

81. Liu S, Yu Y, Gao Y, Yang X, Pang Z. Decreased urinary glycosaminoglycan excretion following alfuzosin treatment on ureteral stent-related symptoms: a prospective, randomized, placebo-controlled study. Urolithiasis. 2016;44(2):185-190. doi:10.1007/s00240-015-0810-4
82. Wang C-J, Huang S-W, Chang C-H. Effects of specific $\alpha-1 \mathrm{~A} / 1 \mathrm{D}$ blocker on lower urinary tract symptoms due to double-J stent: a prospectively randomized study. Urol Res. 2009;37(3):147-152. doi:10.1007/s00240-009-0182-8

83. Gupta M, Patel T, Xavier K, et al. Prospective Randomized Evaluation of Periureteral Botulinum Toxin Type A Injection for Ureteral Stent Pain Reduction. J Urol. 2010;183(2):598-602. doi:10.1016/j.juro.2009.10.021

84. Lee Y-J, Huang K-H, Yang H-J, Chang H-C, Chen J, Yang T-K. Solifenacin improves double-J stent-related symptoms in both genders following uncomplicated ureteroscopic lithotripsy. Urolithiasis. 2013;41(3):247-252. doi:10.1007/s00240-013-0554-y

85. Tae BS, Cho S, Jeon BJ, et al. Does mirabegron relieve ureteric stent-related discomfort? A prospective, randomized, multicentre study. BJU Int. 2018;122(5):866-872. doi:10.1111/bju.14416

86. Ragab M, Soliman MG, Tawfik A, et al. The role of pregabalin in relieving ureteral stent-related symptoms: a randomized controlled clinical trial. Int Urol Nephrol. 2017;49(6):961-966. doi:10.1007/ s11255-017-1561-7

87. El-Nahas AR, Tharwat M, Elsaadany M, Mosbah A, Gaballah MA. A randomized controlled trial comparing alpha blocker (tamsulosin) and anticholinergic (solifenacin) in treatment of ureteral stent-related symptoms. World J Urol. 2016;34(7):963-968. doi:10.1007/s00345015-1704-3

88. Maldonado-Avila M, Garduño-Arteaga L, Jungfermann-Guzman R, et al. Efficacy of Tamsulosin, Oxybutynin, and their combination in the control of double-j stent-related lower urinary tract symptoms. Int Braz $j$ Urol. 2016;42(3):487-493. doi:10.1590/S1677-5538. IBJU.2015.0186

89. Zhang Y-M, Chu P, Wang W-J. PRISMA-combined $\alpha$-blockers and antimuscarinics for ureteral stent-related symptoms: A meta-analysis. Medicine. 2017;96(7):e6098. doi:10.1097/MD.0000000000006098

90. Nevo A, Mano R, Baniel J, et al. Ureteric stent dwelling time: A risk factor for post-ureteroscopy sepsis. BJUI. 2017;120(1):117-122. doi:10.1111/bju. 13796

91. Telescopic insertion or removal of a stent from the ureter. https:// www.baus.org.uk/_userfiles/pages/files/Patients/Leaflets/Ureteric\% 20stent\%20insertion.pdf. (accessed June 2020)..

92. The British Association of Urological Surgeons Stent registry. https:// www.baus.org.uk/professionals/sections/endourology/stent_registry. aspx. Accessed July 20, 2020. (accessed June 2020).

93. Ghosh A, Oliver R, Way C, White L, Somani BK. Results of day-case ureterorenoscopy (DC-URS) for stone disease: prospective outcomes over 4.5 years. World J Urol. 2017;35(11):1757-1764. doi:10.1007/s00345-017-2061-1

94. Geraghty RM, Proiett S, Traxer O, et al. Worldwide impact of warmer seasons on the incidence of renal colic and kidney stone disease: evidence from a systematic review of literature. J Endourol. 2017;31(8):729-735. doi:10.1089/end.2017.0123

95. Baston EL, Wellum S, Bredow Z, et al. Office-based ureteric stent removal is achievable, improves clinical flexibility and quality of care, whilst also keeping surgeons close to their patients. Cent Eur J Urol. 2018;71(2):196-201.

96. El-Nahas AR, El-Assmy AM, Shoma AM, et al. Self-retaining ureteral stents: analysis of factors responsible for patients' discomfort. $J$ Endourol. 2006;20(1):33-37. doi:10.1089/end.2006.20.33

97. El-Nahas AR, Lachine M, Elsawy E, et al. A randomized controlled trial comparing antimicrobial (silver sulfadiazine)-coated ureteral stents with non-coated stents. Scan J Urol. 2018;52(1):76-80. doi:10.1080/21681805.2017.1376353 


\section{Publish your work in this journal}

Research and Reports in Urology is an international, peer-reviewed, open access journal publishing original research, reports, editorials, reviews and commentaries on all aspects of adult and pediatric urology in the clinic and laboratory including the following topics: Pathology, pathophysiology of urological disease; Investigation and

Submit your manuscript here: https://www.dovepress.com/research-and-reports-in-urology-journ treatment of urological disease; Pharmacology of drugs used for the treatment of urological disease. The manuscript management system is completely online and includes a very quick and fair peer-review system, which is all easy to use. Visit http://www.dovepress.com/ testimonials.php to read real quotes from published authors. 